\title{
CURRÍCULO DE HISTÓRIA E EDUCAÇÃO PARA O PATRIMÔNIO
}

Ivo Mattozzi*

RESUMO: Quantas potencialidades tem o currículo de história em relação à educação para o patrimônio? Como o professor de história pode realizar este compromisso? Com qual progressão dos conhecimentos significativos e das operações cognitivas? Com quais estratégias didáticas? Com quais processos de aprendizagem? Para responder a tais perguntas, raciocinarei, primeiramente, sobre a relação entre as marcas do passado, o território, os bens culturais e o patrimônio, valendo-me, principalmente, das contribuições de Cicerchia (2004), Branchesi (2006), Gardner (1991; 1993), Nardi (1996) e Pansini (2004). Os quatro termos compõem um mapa conceitual que pode orientar as escolhas curriculares, nos diferentes níveis da educação básica. A seguir, apresentarei, em linhas gerais, uma proposta de currículo que vimos amadurencendo ao longo dos anos de atividade docente e de pesquisadores (I. MATTOZZI, e TONTO, G. Di (a c. di), 2000; MATTOZZI, I. (a cura di), 2005; MATTOZZI, I. 1990; MATTOZZI, I. 1990), ressaltando como esta pode servir para a educação para o patrimônio e contribuir para a formação histórica de crianças e adolescentes.

Palavras-chave: Educação para o Patrimônio; Ensino de História; Currículo de História; Eucação para o Patrimônio e Cidadania.

\section{HISTORY STUDY PROGRAM AND HERITAGE EDUCATION}

ABSTRACT: What are the different potentials of history study programs concerning the heritage education? How can history teachers fulfill this commitment? What is the progress of meaningful knowledge and of cognitive operations? Which educational strategies are to be used and with which learning processes? To answer these questions, I will first analyze the relation between marks of the past, territory, cultural goods, and heritage based on the contributions of CICERCHIA 2004, BRANCHESI 2006, GARDNER 1991 and 1993, NARDI 1996, and PANSINI 2004. These four aspects make up a conceptual map that may guide study program choices at the different levels of basic education. Next, I will briefly present a study program proposal that I have developed along the years as a history teacher and researcher (I. Mattozzi, and TONTO, G. Di (a c. di), 2000; MATTOZZI, I. (a cura di), 2005; MATTOZZI, I. 1990; MATTOZZI, I. 1990). I will point out how it can serve heritage education and contribute to the education of children and teenagers on history.

Keywords: Heritage education/history teaching, history study program/heritage education, heritage education and citizenship

*Professor de Didática da História e História Moderna da Universidade de Bolonha Itália. E-mail: ivo.mattozzi@unibo.it 


\section{MARCAS, TERRITÓRIO, BENS CULTURAIS, PATRIMÔNIO}

O mundo em que vivemos, em todos os seus aspectos, é o resultado de processos que se desenvolveram no passado. Os processos são testemunhados pelas marcas produzidas pelos agentes naturais e humanos e pelas interações que deram dinâmica aos processos: objetos, edifícios, imagens, escritos, sítios, estruturas, paisagens, tradições, sons. Essas marcas estão e se distribuem nos territórios e revelam a sua estratificação e as suas transformações.

Conseqüentemente, o território em que nos movemos é um mundo de marcas produzidas e deixadas pelos eventos naturais do planeta e pelas atividades de grupos humanos que o habitaram: marcas de metamorfoses geológicas e geográficas; marcas de habitações (sítios arqueológicos, centros urbanos, vilas); marcas arquitetônicas; marcas de estradas e organizações hidráulicas; marcas das atividades produtivas (arqueologia da paisagem, arqueologia industrial...); marcas de atividades administrativas (arquivos); marcas das atividades do poder ou dos poderes (arquivos, museus); marcas das atividades religiosas (locais de culto, necrópoles...); marcas das atividades lúdicas e festivas; marcas das catástrofes humanas (erupções vulcânicas, abandonos, terremotos, enchentes, bombardeamentos...). As marcas existem em um território e são submetidas à jurisdição de uma administração cívica, provincial, regional ou estadual.

As marcas, nos processos de produção dos conhecimentos sobre o passado, assumem um valor cognitivo de instrumentos de informação ou, então, valor estético, afetivo ou mesmo simbólico, ou os quatro valores juntos: por isso, se tornam bens culturais, objeto de atenção, de estudos, cuidado, proteção, manutenção e de restaurações pelas instituições e administrações públicas ou privadas.

Os bens culturais são portadores de um tríplice processo: aquele de produção e de uso na origem, o de descoberta e de uso de conhecimento e o de valorização social como bens culturais.

\section{A HISTÓRIA E OS BENS CULTURAIS}

A história tem a ver com as marcas que se tornaram bens culturais em um tríplice modo: 1. são a matéria-prima do conhecimento histórico que se produz mediante a transformação das marcas em instrumentos de informação; 2. como bens culturais ou complexos de bens, são objeto de estudo histórico; 3. estão no território e o identificam nas suas formas. 
O professor pode aproveitar essa ligação entre a história e os bens culturais para incluir no currículo estratégias de pesquisa históricodidática que façam uso dos bens culturais (arquitetônicos, monumentais, de museus, de arquivos...), com o objetivo de orientar os alunos para a produção de conhecimentos que dizem respeito ao território e aos bens culturais ${ }^{1}$.

Os processos de ensino e de aprendizagem que incluem bens culturais são relativos ao território e o devem incluir na atividade formativa. Esses produzem conhecimentos históricos com escala local e dão aos alunos a possibilidade de melhor compreender o cenário da sua vida.

\section{DOS BENS CULTURAIS À EDUCAC̦ÃO PARA O PATRIMÔNIO}

Pode-se fazer uso dos bens culturais, todavia, sem alcançar automaticamente a educação para o patrimônio. Pense-se a experiência de uma turma que faça uso de documentos em um arquivo. Podem conceber o patrimônio arquivístico ou até mesmo o patrimônio cultural trabalhando somente em um pequeno grupo de marcas? Nunca aconteceu nas minhas experiências. E não acredito que possa acontecer sem outras condições. Por isso, devemos procurar compreender quais são as condições e as estratégias para que o estudante passe do uso dos bens culturais à idéia de que esses são parte de um patrimônio muito mais vasto e complexo.

A primeira condição é que as experiências de aprendizagem se desenvolvam com a utilização dos bens culturais originais: monumentos, arquiteturas, fontes de arquivo, peças de museus, sítios arqueológicos, quadros autênticos, etc. A segunda condição é que sejam objeto de observação e de uso para produzir informações. A terceira condição é que esses sejam colocados em relação com o contexto e com a instituição que os tutela. A quarta condição é que se promova a tomada de consciência de que são a minúscula parte de um conjunto muito mais amplo que permite o conhecimento do passado e do mundo, o prazer de conhecer, a fruição estética. As últimas duas condições requerem que se generalize a descoberta do valor dos bens culturais usados e das instituições e dos sujeitos que os tutelam e os estudam.

Por isso, podemos pensar na educação para o patrimônio como uma ascensão de valor...

Mas a condição principal e primordial é que os alunos se conscientizem de que estão ganhando conhecimentos significativos 
graças à presença dos bens culturais e do seu uso. Os conhecimentos devem ser plenos de sentido e devem ser relativos, primordialmente, ao território.

\section{A HISTÓRIA LOCAL E O CONHECIMENTO DO TERRITÓRIO}

Sobre a pesquisa histórico-didática e sobre a importância que a história local exerce na formação da cultura histórica e na formação do bom cidadão, já escrevemos muitas reflexões e já fizemos o balanço de muitas experiências ${ }^{2}$. O que acrescenta o fato de colocá-la em relação com a educação para o patrimônio? Primeiramente, porque os bens culturais são simplesmente marcas que devem ser transformadas em instrumentos de informação, mas se tornam elementos que marcam o território e são o meio de seu conhecimento. Em segundo lugar, porque são considerados parte de um patrimônio difuso no território, em relações com instituições e administrações que têm poderes de gestão de alguns aspectos do território (governos locais, superintendências, direções de museus e de sítios patrimoniais...). Graças ao uso dos bens culturais e graças à educação para o patrimônio, o aluno adquire conhecimentos sobre o território e sobre os problemas da sua gestão e pode tornar-se um cidadão consciente, interessado e crítico.

Proponho-me, agora, por meio de uma organização curricular, apresentar uma visão das implicações do uso didático dos bens culturais e da relação entre esses e a educação para o patrimônio.

\section{CURRÍCULO A PASSOS LARGOS}

\section{Primeira fonte de inspiração: a disciplina}

Precisamos de uma boa fonte de inspiração para projetar o currículo. A fonte de inspiração é nada mais do que a concepção da história. Se a pensamos como matéria consolidada nos manuais, não conseguimos resolver os problemas do currículo e nele navegar. Por exemplo, como podemos decidir sobre o que fazer nas primeiras fases da escola, se decidimos desconsiderar os conhecimentos dos livros? Se pensamos que o índice do manual é progressivo, como fazemos para decidir se a estrutura dos conteúdos é aquela adequada para os níveis escolares sucessivos? E como fazemos para distribuir e organizar os conhecimentos para os planos de trabalho plurianuais e anuais? Devemos emancipar-nos da idéia de que a história coincida com a matéria escolar (portanto, com o sistema de conhecimentos do manual) e assumir outra idéia de história, muito mais produtiva, aquela de disciplina de pesquisa e 
de estudo. Eu proponho esta condição: a história é a disciplina que tem a finalidade de produzir conhecimentos sobre aspectos, fatos e processos do passado, mediante procedimentos regulados e controláveis e operações cognitivas e práticas de organização das informações e dos conhecimentos. Essa nos coloca à disposição os produtos da atividade intelectual, em geral, sob forma de textos. Para compreender os textos históricos e apreender os conhecimentos, os alunos devem aplicar as operações cognitivas e práticas, de modo a transformá-las em mapas mentais disponíveis para ser comunicáveis, reorganizáveis e usáveis. As operações cognitivas são muitas: as principais são aquelas da tematização, das temporalidades, das espacializações, aquelas de classificação dos fatos em mutação e permanências, aquelas de inferência, da problematização e da explicação.

Uma primeira conseqüência curricular é esta: o aprendizado intelectual exigido pela história pode começar no exercício das operações cognitivas e práticas de organização das informações, não considerando os conhecimentos contidos nos livros.

A segunda conseqüência é que tais habilidades são promovidas e sustentadas em virtude e em relação com os textos históricos.

Mas a história pensada como disciplina nos libera do leito de contenção do universo e do sistema de conhecimentos do manual. De fato, a disciplina produz uma quantidade de conhecimentos disponíveis muito mais ampla do que aquela contida nos manuais e coloca à disposição conhecimentos e sistemas de conhecimentos com múltiplas configurações que podem ser consideradas no momento de decidir sobre quais conhecimentos são adequados para os diversos níveis escolares.

\section{Segunda fonte de inspiração: a personalidade das crianças e dos adolescentes}

Para podermos pensar no currículo, devemos ter clara idéia sobre quais são as potencialidades cognitivas iniciais das crianças e sobre como podem envolver-se em habilidades de pesquisa e de estudo.

No início, na educação infantil e nas primeiras séries do ensino fundamental, os alunos são dotados de capacidades cognitivas temporais (por exemplo, as crianças sabem colocar em seqüência ações para alcançar um objetivo...), espaciais (por exemplo, sabem deslocar-se de um lugar para outro da casa ou da escola, demonstrando ter mapas mentais...), sabem distinguir entre os fatos que implicam uma mudança, fazem imitações ou sabem scripts de várias experiências, fazem inferências: elaboraram as suas habilidades e teorias sobre o mundo, graças à interação 
discursiva e pragmática com os adultos e com os coetâneos. Eles estão, portanto, dispostos a aproveitar dos estímulos que podem promover e aumentar as habilidades e os conhecimentos de mundo. Aos professores caberá inventar e programar atividades de aprendizagem que coloquem no centro a reflexão e a representação das experiências dos estudantes. Este é o ponto de partida da aventura curricular. Em seguida, haverá o encontro com conhecimentos históricos e com seus procedimentos de produção, que, aos poucos, devem apresentar a configuração mais adequada aos níveis de maturidade cognitiva e às habilidades já formadas nos adolescentes, que têm relação freqüente com os bens patrimoniais, muitas vezes sem perceberem e, por vezes, conscientemente.

\section{AS FASES DO CURRÍCULO}

\section{A formação da disposição ao estudo da história}

Se a história é processo de construção de representações de aspectos, fatos e processos do passado por meio de operações cognitivas e práticas que se aplicam às marcas e às informações produzidas e se os estudantes dispõem de capacidade de realizar as operações cognitivas exigidas pelo viver cotidiano, então podemos arquitetar uma fase curricular em que se formam as disposições ao estudo da história. Esta pode durar desde a educação infantil até a quarta série.

\section{A formação do primeiro saber histórico}

Se o conhecimento histórico nos possibilita diversas formas de organização, então devemos especificar aquelas que se mostram mais adequadas para as capacidades iniciais dos alunos e mais adaptadas a construir um primeiro sistema de saber. Argumento que a configuração mais conveniente é aquela dos quadros de civilização, em que o sistema do saber se constrói dispondo os quadros estudados em um mapa espaçotemporal do passado do mundo, analisando a relação entre as civilizações conhecidas e construindo periodizações. Esta fase coloca-se entre o final da terceira até a quinta série.

\section{A formação do segundo saber histórico}

Presumimos que os estudantes que exercitaram as habilidades cognitivas e práticas e que descobriram o passado do mundo com os quadros de civilizações e o mapa espaço-temporal sejam capazes de enfrentar conhecimentos históricos mais complexos, como aqueles que dizem respeito à transformação do mundo. Estes se configuram como 
textos que dizem respeito aos processos de grande transformação e, sendo dispostos juntos no mapa espaço-temporal, representam a transformação do mundo (por meio de tais processos, transformou-se como é atualmente) e permitem formar os quadros cronológicos que lhe dizem respeito.

\section{A formação do terceiro saber histórico}

Aos estudantes que possuam domínio sobre os grandes processos de transformação e dos quadros cronológicos, não é o caso de repropor o estudo dos mesmos processos de transformação segundo a repetição cíclica que faz parte da tradição escolar. Podemos mirar nas suas habilidades e nas suas disposições psicológicas, a fim de sondar problemas para promover um saber histórico mais denso: aquilo que se pode compor com os conhecimentos que dizem respeito aos problemas históricos, às explicações e às interpretações.

A progressão curricular deve satisfazer a exigência de conduzir os alunos em uma seqüência de processos de aprendizagem que prometem alcançar, com êxito, a cultura histórica entendida como posse e domínio

- do uso dos conhecimentos significativos e do sistema de conhecimentos;

- dos quadros cronológicos prontos a integrar novos conhecimentos;

- das habilidades para realizar operações de produção e organização das informações sobre o passado;

- das habilidades operacionais para o uso de instrumentos de organização das informações e dos conhecimentos.

O currículo que propomos apresenta cinco formatos de conhecimentos significativos diversos, cada um feito para uma fase da progressão formativa: - calendários, imitações, reconstrução de experiências vividas para a educação infantil e as séries iniciais do Ensino Fundamental;

- reconstruções de aspectos e de processos de mudança do passado da geração dos alunos nas séries $1^{\mathrm{a}}$ e $2^{\mathrm{a}}$ e, logo após, daquela dos adultos $3^{\mathrm{a}} \mathrm{e} / \mathrm{ou}$ $4^{\mathrm{a}}$ série;

- os quadros de civilização para as séries finais $3^{\mathrm{a}}-5^{\mathrm{a}}$ séries;

- os processos de transformação para as séries $6^{a}, 7^{a}$ e $8^{a}$;

- os temas e os problemas para o Ensino Médio.

Obviamente, esta é somente uma progressão teórica que pode ser modificada de acordo com as disponibilidades das turmas, e cada um dos formatos pode ser aplicado também para os outros níveis: os teatros são úteis mesmo após a primeira série, assim como precisa-se de quadros de civilização para entender os processos de transformação, os temas e os 
problemas. E os processos de transformação poderiam ser propostos no Ensino Fundamental com muita simplicidade, e com mais complexidade no Ensino Médio e assim por diante.

O importante é que os conhecimentos sejam organizados para que sejam significativos para os estudantes; isto é, que respondam a problemas formulados ou compartilhados pelos discentes e que sejam usáveis para compreender o mundo atual e os outros conhecimentos históricos.

O currículo propõe abordar a construção dos conhecimentos mediante fontes ou, até mesmo, mediante o estudo dos conhecimentos contidos nos livros: em ambos os casos, com a aplicação de operações mentais de produção e organização das informações.

\section{O CURRÍCULO PASSO A PASSO}

A formação das disposições ao estudo da história é feita comprometendo os alunos da educação infantil e das primeiras séries do ensino fundamental para a construção e a leitura de "calendários", de "peças teatrais", de "reconstruções e representações de experiências vividas". O objetivo é dar ocasiões para o exercício do pensamento temporal e espacial, além de enriquecer o tesouro de conhecimentos significativos sobre o mundo vivido.

Calendários das atividades quotidianas: assim são chamadas as representações de seqüências de atividades que o grupo dos estudantes desenvolve dia após dia e ao longo das semanas. São representações não-cronológicas, construídas pelas crianças mediante ícones e desenhos de gênero variado. Contêm a organização temporal segundo sucessão e ciclo, e a organização espacial segundo os locais em que as atividades se situam. São conhecimentos significativos, pois dão às crianças a possibilidade de fazer previsões sobre o futuro e de acalmar as ansiedades que derivam do não saber administrar o intervalo entre o ingresso na escola e o encontro com os parentes...

Calendários das esperas: com o modelo do calendário de acontecimentos, pode-se preparar com as crianças um instrumento para contar quantos dias faltam para um evento esperado (aniversário, festividades, excursões...). Isso promove o sentido do futuro.

Peças teatrais ou scripts: são as representações de experiências repetidas, vividas ou sentidas que se reproduzem de modo estereotipado (por exemplo, pegar o trem, ir ao supermercado, ir tomar sorvete, ir ao mercado, ao cultivo, à vindima...). As representações se produzem mediante operações de ordenação temporal e espacial que organizam as 
ações segundo os agentes, a sucessão, os espaços diversos nos quais essas acontecem. São um potente instrumento para conhecer o mundo, entender os discursos e os textos, fazer inferências e previsões... É possível orientar os estudantes a produzir peças teatrais de experiências vividas ou então daquelas contadas.

Reconstruções de experiências: este é um processo de aprendizagem que estimula a pesquisa e a construção do conhecimento histórico, transpondo-o didaticamente de modo que seja na medida dos alunos: os objetos abordados são as experiências vividas pelo grupo da turma, as marcas são aquelas produzidas pelos alunos, as operações de produção das informações são orientadas e induzidas pelo professor, o registro pode acontecer mediante desenhos e/ou breves frases (quando sabem escrever), a organização temporal consiste em montar os desenhos ou as fichas escritas em um gráfico temporal, a comunicação pode acontecer de modo oral, comentando o gráfico. Dessa forma, os alunos transformam as marcas em instrumentos de informação e procedem à construção de conhecimento sobre o passado, elaborando operações cognitivas e exercitando-as em atividades práticas.

O calendário como instrumento de medida: desde os calendários nãocronológicos das atividades até o primeiro saber cronológico, com a compreensão da estrutura do calendário como instrumento de medida, baseado nas séries de mudanças regulares e cíclicas dos fenômenos celestes ligados aos aspectos do Sol e da Lua. É a primeira aproximação da compreensão da diferença entre organização temporal dos fatos e organização cronológica baseada em datas. Esta é fundada na organização temporal de fenômenos celestes cíclicos, como o movimento aparente do Sol e da volta celeste e a sucessão das fases lunares. O calendário é uma representação disso tudo, e as crianças deveriam ser orientadas para a observação e para o registro, a fim de que compreendam o objetivo e a arquitetura do calendário.

Reconstruçoes de aspectos e de processos de mudança: a pesquisa histórico-didática, anteriormente experimentada em relação ao passado imediato, pode ser aplicada em um horizonte temporal cada vez mais profundo. Em primeiro lugar, para que os estudantes reflitam sobre as transformações vividas por eles no primeiro ano de escola ao passarem do analfabetismo à alfabetização. No início da segunda série, é possível dar à classe o dever de reconstruir, representar e comunicar como, em quanto tempo, com qual progressão a comunidade aprendeu as habilidades de escrever ou de fazer contas. 
A seguir, pode-se abordar algum processo de mudança relativo ao passado da geração das crianças para uma profundidade de oito anos. É a reformulação da didática tradicional em relação ao passado pessoal. A diferença é que não se trata de fazer uma lista de pequenos eventos, mas de selecionar as informações segundo uma tematização significativa e de fazer com que as crianças compreendam que os aspectos e as mudanças de cada biografia são compartilhados por aqueles da mesma geração.

Os conbecimentos prévios sobre o passado do mundo: no momento da primeira aproximação ao estudo dos conhecimentos disciplinares, é necessário levar em consideração aquilo que os estudantes aprenderam fora da escola sobre o passado do mundo: informações, conceitos, imagens mentais, inferências mais ou menos válidas ou concepções devem ser consideradas em uma conversa e devem transformar-se em objeto de reflexão, por meio da organização dos desenhos que as representam em seqüências temporais não-cronológicas. Esta atividade é útil para que se possa compreender como as crianças pensam sobre as informações recebidas, quais operações cognitivas e práticas sabem fazer, e para que elas se sintam curiosas em relação a novos conhecimentos que devem ultrapassar e corrigir aqueles que constituem o estado cognitivo anterior aos processos de ensino e aprendizado em relação "à história".

O segundo saber cronológico: os conhecimentos históricos são organizados temporalmente por meio de datações e, nos livros, os estudantes encontram datas formuladas de grande variedade de maneiras (X anos atrás, $\mathrm{X}$ a.C., séc. $\mathrm{XX}$, décadas, século, milênio, etc.). A compreensão e o conhecimento cronológico histórico constituem requisito para enfrentar o estudo dos livros históricos. Ocorre, porém, formar laboratorialmente o segundo saber cronológico antes de começar com os conhecimentos.

O conhecimento do planisfério: o saber histórico diz respeito a grupos humanos que viveram em locais diversos da superfície terrestre. Portanto, os estudantes encontram nos livros localizações e distribuições das civilizações que podem compreender somente se souberem usar o planisfério e o globo para situá-las. É indispensável trabalhar no laboratório para formar as habilidades da leitura e do uso do planisfério.

O quadro da civilização atual: os estudantes precisam de um modelo de quadro de civilização e precisam conhecer os procedimentos, as práticas e os instrumentos para construí-los. Como dotá-los das habilidades, do saber procedimental, do modelo? A nossa resposta é: orientando-os para a construção da representação do quadro da 
civilização no qual as crianças são imersas. É necessário que, com atividades laboratoriais, eles consigam especificar os aspectos caracterizantes a serem descritos, produzam as informações, levando em consideração suas experiências, as registrem em fichas (pode ser também post-it), as coloquem em um pôster ou cartaz, leiam o quadro como mapa conceitual e caracterizem as relações entre os diversos aspectos. Neste ponto, são maduros para compreender as civilizações remotas.

O saber histórico construido com os quadros de civilização: no primeiro contato com os livros históricos, é oportuno que os estudantes encontrem conhecimentos configurados de maneira a corresponder às suas capacidades de compreendê-los. Estes consistem nas descrições das características dos modos de vida dos grupos e dos povos em espaços e períodos bem determinados. Os livros descritivos das civilizações são instrumentos de aprendizagem. Mas, para apreender os conhecimentos, os estudantes devem ser orientados a aprender a usá-los para transformálos em mapas mentais disponíveis para a comunicação oral ou escrita. Convém, portanto, comprometê-los em atividades laboratoriais para ensiná-los a selecionar e a registrar as informações em fichas para, depois, transportá-las para um cartaz ou pôster que represente o mapa conceitual da civilização. Não basta, porém, que leiam, utilizem livros e façam pôsteres para que os estudantes formem o sistema de conhecimento que lhes dê condições de ter uma visão de totalidade do passado do mundo e da sua periodização. É necessário ensinar a usar os conhecimentos por meio de duas atividades: 1. a comparação entre quadros de civilizações; 2. a construção do mapa espaço-temporal.

A comparação entre os quadros de civilizações: os estudantes comparam dois quadros de civilizações posteriores e podem perceber permanências e mudanças; ou mesmo comparam civilizações contemporâneas e então encontram semelhanças e diferenças. Os resultados da comparação transformam-se em base de dados e estímulos à formulação de questões e à determinação de relações entre aspectos das civilizações comparadas.

O mapa espaço-temporal do passado do mundo: o saber histórico consiste não somente em possuir determinados conhecimentos, mas também em colocá-los em relação para construir conhecimentos ordenados e sistematizados que dizem respeito aos estados do mundo em certos períodos e às suas transformações de um período ao outro. Para que tal objetivo seja alcançado, é necessário que o professor administre também o processo de aprendizagem do sistema de conhecimento e induza os estu- 
dantes às práticas e reflexões que tenham como êxito as correlações entre os conhecimentos e a representação ordenada do passado. O instrumento organizador é o mapa espaço-temporal em que a linha cronológica e aquela dos espaços continentais constituem os eixos cartesianos no cruzamento dos quais estão os ícones e/ou as notícias relativas a eventos e civilizações indicadas na sua duração. Dessa maneira, os alunos produzem uma visão sinótica que permite periodizar a série das civilizações e dar respostas a perguntas sobre os estados do mundo (por exemplo, quantos povos havia no mundo mediterrâneo no final do século IV a.C.?) e sobre as transformações ocorridas em certos tempos (por exemplo, como cresceu o Estado romano do século III a.C. ao século II d.C.?).

O saber histórico constituído de processos de grande transformação: um resultado desejado do aprendizado é o conhecimento da transformação do mundo e dos quadros cronológicos em que pode ser decomposto. Da escola de base, os alunos deveriam sair com uma cultura histórica da qual é elemento cardinal o conhecimento dos processos da transformação. A representação de cada transformação é formada por dois "estados de coisas" (inicial e final) e por uma série de mudanças que os unem. Tratase de encontrar o formato do conhecimento e do texto eficaz para tornálos significativos. O curso de história pretende, pois, ser uma narração da transformação e pretende fazer perceber como o mundo era em um tempo inicial (por exemplo, na pré-história) e como mudou em um tempo sucessivo (por exemplo, no mundo atual). No entanto, o que se observa é que dispõe a narração, geralmente, sem descrever os estados das coisas, dividindo os processos em segmentos breves, montados em uma ordem incoerente para obedecer ao princípio de estruturação, constituído pela ordem cronológica dos inícios dos fatos e dos eventos. Conseqüentemente, a montagem dos conhecimentos no manual é fator de perda do seu significado e incentivo de perda dos leitores. Para remediar esses inconvenientes e para reduzir a quantidade dos temas a serem ensinados e a serem aprendidos, propomos especificar e construir processos de grande transformação. Isto é, abordá-los no longo período e nos amplos espaços de observação, de forma a serem significativos para os alunos, pois dão conta de transformações que levam ao mundo atual. Esses são constituídos por blocos discursivos mais ou menos longos que apresentam:

- a tematização;

- a relação entre conhecimento do presente e conhecimento do passado;

- o estado da coisa inicial (estado A);

- o estado da coisa final (estado B); 
- a comparação entre os dois estados para identificar as permanências e as mudanças;

- a formulação de questões;

- a periodização como síntese do processo;

- a seqüência das mudanças que levam do estado A ao estado B;

- a relação entre conhecimento do passado e conhecimento do presente.

O mapa espaço-temporal dos processos de transformação: o sistema de conhecimentos deve ser objeto de ensino e de aprendizagem, para que os estudantes usem os conhecimentos para perceberem as transformações complexas que constituem a evolução do mundo. Em cada ano escolar, é necessário que os alunos organizem os processos de transformação estudados aos poucos sobre um mapa espaço-temporal que permita colocá-los em relação, vê-los no conjunto, periodizar a transformação global, colocá-la em relação com o conhecimento de aspectos e de processos do mundo atual. A cada ano, o mapa se enriquece e, ao final, se oferece a uma leitura e a uma memorização de períodos, de seqüências de transformações, de contemporaneidade dos processos, de contextos... Em suma, um quadro capaz de integrar ordenadamente novos conhecimentos e de orientar na história.

O terceiro saber histórico construido com os problemas e as explicaçoes: o ensino médio, principalmente nos últimos anos, é a fase em que é possível promover com maior intensidade o pensamento histórico dos alunos. Esses podem ser orientados à compreensão de como funciona o raciocínio e a interpretação dos historiadores. A disciplina histórica é uma atividade intelectual direta para produzir, em primeiro lugar, conhecimentos monográficos que constituem matéria-prima para a construção de histórias gerais, como aquelas que estão na origem dos sistemas dos conhecimentos dos manuais. Os conhecimentos monográficos bem-arquitetados pelos historiadores contêm sempre a referência ao conhecimento do presente, à reconstrução dos fatos, à problematização, à hipótese explicativa. A interpretação está presente em toda parte, mas se fortalece na problematização e na explicação que são expostas mediante argumentações muito articuladas. A reconstrução dos processos da transformação absorve muitos recursos e muito tempo e não permite fazer aprofundamentos sobre os problemas e as explicações de cada processo. Por isso, convém aproveitar o período em que, nos adolescentes, se manifesta prepotente o desejo de problematizar para compromissá-los no estudo dos problemas, das explicações históricas e das controvérsias interpretativas entre os historiadores. Pode-se 
desenvolver tal programa se se renuncia à réplica do curso de história geral sob forma de processos de transformação e se seleciona-se uma série de problemas a serem estudados nos seus contextos e processos. A composição de uma unidade de aprendizado se torna:

- tematização clara e compartilhada;

- relação entre conhecimento do presente e conhecimento do passado;

- levantamento dos conhecimentos prévios;

- descrição do contexto ou dos contextos;

- descrição do estado A;

- descrição do estado B;

- comparação entre os dois estados e levantamento das permanências e das mudanças;

- formulação de problemas

- reconstrução dos fatos espaçados (periodização) ou próximos;

- segunda problematização do início, ou então de alguns andamentos ou momentos do processo, ou então da conclusão;

- comparação da problematização dos estudantes à problematização de um especialista;

- hipótese de explicação de um historiador;

- comparação de explicações alternativas;

- relação entre conhecimento do passado e conhecimento do presente ou com os outros conhecimentos do passado.

Os quadros cronológicos e a rede de conhecimentos: os fatos problematizados podem ser colocados nos mapas espaços-temporais que os estudantes continuam a usar para refinar e enriquecer os quadros cronológicos e para raciocinar sobre a rede de conhecimentos históricos apreendidos. Assim, sua cultura se constitui de habilidades cognitivas e práticas, de conhecimentos de fatos, processos e problemas, de capacidade de estabelecer nexo entre os conhecimentos, conhecimento dos procedimentos de construção do saber histórico, conhecimentos dos modos de raciocinar dos historiadores...

É evidente que o currículo se caracteriza pela continuidade e pelo desenvolvimento das habilidades para executar operações de produção e de organização das informações e para a contínua pesquisa com a finalidade de construir conhecimentos que tenham sentido. Os alunos exercitam, em cada ponto do currículo, as operações cognitivas para organizar as informações: tematização, estruturação temporal, estruturação espacial, transformação das marcas em fontes, produção de informações diretas e de inferência, elaboração das informações, classificação dos fatos em mudanças, eventos, permanências; problematização; explicação; comunicação. E, em cada ponto, manifestam 
tais operações com práticas operacionais e com a construção ou o uso de mediadores instrumentais de organização das informações (fichas, gráficos temporais, esquemas, mapas, tabelas, cartografia...). Compreendem, a cada vez, o significado que é atribuído ao conhecimento a ser apreendido, mas, de nível em nível, são estimulados também pela diversidade dos conhecimentos históricos e dos seus formatos. Porém, os conhecimentos e o sistema formados em um nível produzem frutos no nível seguinte como benefício da compreensão e da construção de outros conhecimentos e de sistemas mais complexos.

\section{O PATRIMÔNIO NO CURRÍCULO}

Como pode o currículo assim estruturado e articulado servir para a educação para o patrimônio? E como pode o patrimônio prestar um serviço para a formação histórica?

Pode ser funcional à educação para o patrimônio se aceita recorrentemente bens culturais entre os seus objetos e instrumentos. Por um lado, o patrimônio contribui potencialmente na formação histórica, visto que permite dar consistência às informações e abstrações dos textos históricos e porque constrói a percepção e a visão histórica do território e do mundo. O escopo é gerar o sentido, o conhecimento e o respeito ao patrimônio. Este pode ser o resultado de uma relação recorrente com ampla e variada gama de bens patrimoniais e de instituições que os tutelam e estudam. A relação deveria ser caracterizada pelo contato direto com os bens, pela fruição cognitiva e estética, pela descoberta do valor simbólico e afetivo. Mas o sentido do patrimônio deve ser incrementado mediante o uso da multimídia.

Instalemos, ora, em cada ponto do currículo, os bens patrimoniais.

Peças teatrais: já na educação infantil e nas primeiras séries do Ensino Fundamental, os bens patrimoniais podem ser integrados às atividades de formação graças à didática das peças de teatro.

As crianças podem ser orientadas a descobrir alguns bens do território (por exemplo: torre cívica, muros urbanos, sinos, igrejas, teatros, monumentos, figurações pictóricas, capitéis... castelos e moinhos...) e conhecer suas funções e seu uso, mediante a construção das peças teatrais que se referem aos agentes que as usavam. Pensou-se na possibilidade do local de um moinho hidráulico: as crianças poderiam conhecer as funções das partes principais e os agentes que as usavam graças às histórias que podem ser transformadas em teatros e em embriões conceituais que 
fazem compreensíveis outros textos que citam moinhos ou, então, a visita a outros moinhos. Teatros podem ser construídos de acordo com a observação de imagens pintadas ou esculpidas ou representadas pela história. Não importa se as imagens foram reproduzidas, basta que sejam por bens culturais e de boa qualidade: a exploração, a observação, a interpretação iconográfica são exercícios importantes para construir a capacidade de dar sentido e de começar a registrar a variedade dos estilos.

Calendários: os calendários dos trabalhos agrícolas esculpidos ou ilustrados ou decorados com afrescos ou impressos, diretamente observáveis ou então legíveis mediante reprodução digital, podem tornarse a base para construir peças de teatro dos trabalhos dos camponeses, mas também para a descoberta de expressões e de técnicas artísticas que alimentam o sentido do passado. Por exemplo: "Les Très riches Heures" (ilustradas pelos irmãos Limbourg para o duque de Berry) são “...uma máquina visual que nos reconta a vida de uma época. Nenhum filme poderá igualar a fidelidade, o fulgor, a tocante beleza desta reconstrução" (Umberto Eco) e a seqüência das suas imagens está disponível na web³.

Reconstrucões mediante pesquisa histórico-didática: são atividades que requerem o uso de bens culturais como instrumentos para a produção de informações. Estas, além disso, podem fazer de bens os objetos do conhecimento. Nesses casos, os estudantes certamente não devem utilizar obras impressas para a aquisição de informações em fonte extra e também em fontes de arquivo, de bibliotecas e arquivos, e podem recorrer a uma gama de outros bens com o objetivo de produzir a base de dados a serem organizados em conhecimentos. Esses trabalham na melhor condição para descobrir a existência dos bens, suas funções, relações com o território e com a sociedade que o habita, a atividade de institutos como as bibliotecas, os arquivos, os museus, as superintendências...

Quadros de civilização: existem as civilizações de grupos humanos pré-históricos, as civilizações itálicas e a romana, que podem ser reconstruídas mediante explorações e observações e produção de dados nos sítios arqueológicos, nos museus, em bibliotecas...

Com a construção de quadros de civilizações, principalmente o território regional, por inteiro, é considerado e se torna o cenário no qual os bens culturais e as atividades que lhes dizem respeito são colocados. Mas as civilizações desenvolvidas em espaços longínquos podem ser estudadas mediante imagens multimídia de bens culturais: deste modo, se enriquecem a tomada de consciência e o conhecimento da complexidade do patrimônio. 
Processos de transformação: as pesquisas e os estudos podem abordar preferivelmente aspectos e transformações territoriais que permitem aos estudantes entrar em contato com os arquivos (escolarcorrente e histórico-paroquial, da prefeitura e do estado...) e/ou com edifícios, e/ou com bairros históricos, e/ou museus, e/ou sítios arqueológicos, e/ou com monumentos e com bibliotecas... Grandiosos fenômenos como a cristianização do império, a formação de castelos, o desenvolvimento das cidades medievais, o Humanismo e o Renascimento, o desenvolvimento das cortes de príncipes e a formação dos estados regionais, a formação das paisagens agrárias, as revoluções científicas, a difusão da arte tipográfica, a revolução cartográfica, a difusão de novas culturas, os engenhos hidráulicos, o desenvolvimento da civilização das vilas, a formação dos centros manufatureiros e industriais, as melhorias nos terrenos, as novas urbanizações novecentistas, o desenvolvimento econômico de ' $900 \ldots$ podem ser o foco de atividade de ensino e aprendizagem que se pode rejuvenescer de complexos inteiros patrimoniais: igrejas, castelos, cidade, série de pinturas, fundos bibliotecários antigos, arquivos, centros históricos, palácios, paisagens, museus de todos os tipos.

Problemas: não existem limites de aplicação aos bens patrimoniais quando são organizados os processos de ensino e de aprendizagem em relação aos problemas. Aliás, as atividades didáticas podem ser referentes ao patrimônio como problema com todas as questões a elas correlatas... Os estudantes podem tornar-se autônomos na pesquisa do arquivo ou biblioteca, podem aproveitar algumas excursões escolares para descobrir patrimônios em regiões ou países diferentes daqueles de residência, podem afrontar as questões inerentes ao governo do patrimônio em nível local e nacional...

É evidente que, segundo tal inspiração curricular, um estudante começa a ter experiências de fruição cognitiva e estética de bens patrimoniais na Educação Infantil e as continua de ano em ano, ampliando e diversificando a gama dos bens. Isso lhe permite colocar em tensão repetidamente as habilidades de observação e de análise, de produção das informações, de avaliação estética, de estabelecimento de correlações entre os diferentes bens, de entendimento de sua função, de seu valor social e da necessidade de cuidados pelos cidadãos e pelas administrações... 


\section{AS ESTRATÉGIAS DIDÁTICAS}

A presença do patrimônio nos processos de ensino e de aprendizagem da história pode ter efeitos formativos importantes, já que influencia também a mediação didática, predispondo os professores a uma interação mais intensa com a classe.

O professor deve definir, em primeiro lugar, a cada ano, pelo menos um tema cujo desenvolvimento imponha e legitime o uso de qualquer bem patrimonial. A sua segunda inspiração é aquela de "adotar" os bens a serem utilizados, como faz com os livros didáticos, isto é, com o empenho de compartilhá-los com os alunos. Mas, por sorte, o patrimônio como objeto e como instrumento de informação não pode ser usado como um livro didático. Os estudantes devem ser empenhados a descobri-lo e a usufruir isso com um corpo-a-corpo que coloque em jogo sentidos, mente e práticas. Por isso, as estratégias didáticas são importantes e não podem ser transmissivas. A transmissão das informações durante a visita não pode ser considerada suficiente. $O$ conceito-chave é o uso construtivo dos bens culturais. A construção de conhecimentos comporta o ônus e o prazer de orientar a classe em percursos de procedimentos, em uso de instrumentos, raciocínios, práticas comunicativas que requerem a programação de atividades laboratoriais. O laboratório torna-se o ponto crucial dos processos, aquele que forma as habilidades a serem investidas na observação, na análise e na interpretação dos bens patrimoniais.

\section{EDUCAR PARA A HISTÓRIA E PARA O PATRIMÔNIO}

Um currículo dessa forma arquitetado insere, no campo de atenção dos estudantes, ampla gama de bens como amostras do patrimônio. Mas a educação para o patrimônio se obtém quando a mente transita do bem ou dos bens estudados ao complexo patrimonial do qual fazem parte e às instituições e a administrações que providenciam seu estudo, sua tutela, sua gestão. Por isso, cada processo de aprendizagem deveria ser concluído com procedimentos de generalização que, de acordo com o conhecimento em escala local, fazem compreender tanto fenômenos de escala ampla quanto a existência de outros bens culturais do mesmo tipo daqueles estudados localmente.

Alguns exemplos: se se constrói um quadro da civilização itálica romana usando sítios e museus arqueológicos locais, pode-se chegar à generalização mediante o uso de cartas geo-históricas que reconhecem a presença de outras civilizações e mediante mapas arqueológicos que 
mostram que estas são conhecidas graças a sítios e a museus difundidos em cada região.

Se o processo se refere à formação de castelos em escala local, a generalização pode ser promovida mediante mapas dos burgos em torno aos castelos, etc.

Assim, a passagem do uso dos bens à concepção do patrimônio na aprendizagem da história pode formar um jovem que organiza o passado histórico em quadros cronológicos, conhece os principais processos de transformação que consideram o progresso do mundo, sabe argumentar sobre alguns dos mais relevantes problemas históricos, sabe que existem muito mais conhecimentos históricos do que aquilo que já estudou, conhece os procedimentos de construção do conhecimento, é capaz de usar os conhecimentos para interpretar os processos em curso, criticar os conhecimentos históricos, adquirir e integrar novos conhecimentos históricos, viver na história como cidadão atento às relações entre conhecimento do presente e do passado, estar atento às razões do valor cultural do patrimônio, respeitando-o e preservando-o. Enfim, um jovem formado na história, educado para o patrimônio e pronto para exercer a cidadania democrática.

\section{REFERÊNCIAS}

\section{Sobre o patrimônio e educação para o patrimônio}

BRANCHESI, L. (a cura di), Il patrimonio culturale e la sua pedagogia per l'Europa. Bilancio e prospettive. Roma: Armando, 2006.

BRANCHESI, L. La pedagogia del Patrimonio in Europa. In: COSTANTINO M. (a cura di). Mnemosyne a scuola. . Milano: Irrsae del Lazio, FrancoAngeli, 2001.

CICERCHIA, A. Il bellissimo vecchio. Argomenti per una geografia del patrimonio culturale. Milano: FrancoAngeli, 2002.

GRIMALDI, R. e Trinchero, R. (a cura di). Multimedialità, Telematica e Beni Culturali Alessandria: Ediz. dell'Orso, 1998.

PANSINI, S. Museo e Territorio. Interpretazione e uso dei beni culturali. Bari: Progedit, 2004.

\section{Sobre currículo de História e bens culturais}

MATTOZZI, I. (a cura di). La didattica della storia: insegnare il primo sapere storico. Corso di formazione a distanza, in cdrom. Firenze: Giuntiscuola, 2005.

MATTOZZI, I. G. DI TONTO (a c. di). Insegnare storia, courseware ipertestuale. RomaBologna: MPI-Dipartimento di discipline storiche, 2000.

MATTOZZI, I. La didattica dei beni culturali: alla ricerca di una definizione apparso, prima, in M. Cisotto Nalon (a c. di), Il Museo come laboratorio per la scuola. Per una didattica dell'arte, Padova, Il Poligrafo, 2000, p. 17-44, traduzido, posteriormente, em espanhol com o título La didáctica de los bienes culturales: a la búsqueda de una definición, In: Museo y patrimonio en la didáctica de las ciencias sociales, (Huelva, Universidad de Huelva, 2001, p. 57 - 
95) ed edito, infine, con qualche revisione e col titolo Verso una didattica dai beni culturali: la definizione del campo della didattica dei beni culturali In: COSENTINO, M. (a c. di), Mnemosyne a scuola. Per una didattica dai beni culturali. Milano: FrancoAngeli, 2001. p. 44-73. MATTOZZI, I. Un curricolo per la storia. Una proposta teorica e resoconti di esperienze. Bologna: Cappelli, 1990.

\section{Sobre Didática dos bens culturais}

CELLA, L. (a cura di), Scopriamo Trento al tempo del Concilio. Gioco di società per la scuola media, Trento: Castello del Buonconsiglio Monumenti e Collezioni provinciali, Settore Didattico, 1999. CISOTTO, M. e MATTOTOZI, I. (a cura di), Al museo gli oggetti mi parlano di Paleoveneti. Materiale didattico per la scuola elementare. Padova: Comune di Padova, 1994.

DE BARTOLOMEIS, F. Girare intorno all' arte: valutare e produrre. Firenze: La Nuova Italia, 1990.

DI BLASI BURZOTTA, R.; I. MATTOZZI (a cura di). Incontri con l'arte islamica, Proposte di lavoro per la scuola secondaria in occasione della mostra "Eredità dell'Islam. Arte islamica in Italia", Venezia: Comune di Venezia, 1993

DI BLASI BURZOTTA, R. I. Mattozzi, (a cura di). Motivi nell'arte di Antonio Canova. Venezia: Comune di Venezia, 1992.

DI BLASI BURZOT'TA, R. MAT'TOZZI, I. (a cura di), Antonio Sant'Elia nel suo tempo. Schede di lavoro per la scuola media superiore (in occasione della mostra su Sant'Elia). Venezia: Comune di Venezia e Comune di Como, 1991.

ECO, U. Museo e comunicazione. In: Il museo parla al pubblico 1989-90. Atti del convegno di Bologna, 19-21, ottobre 1989, Roma, UPI, Provincia di Bologna, Editoriale TEST, 1990. p. 25-32. ECO, U. Osservazioni sulla nozione di giacimento culturale. In: Le isole del tesoro. Proposte per la riscoperta e la gestione delle risorse culturali. Milano: Electa, 1988.

GARDNER, H. Educare al comprendere. Stereotipi infantili e apprendimento scolastico. Milano: Feltrinelli, 1991.

GARDNER, H. Sapere per comprendere. Discipline di studio e discipline della mente. Milano: Feltrinelli, 1993.

GHIGNONE, I. CAPUTO, L La scuola e i beni culturali, prospettive interdisciplinari. Bologna: Clueb, 1982.

LANEVE, C. (a cura di), Beni, culturali e didattica, esperienze e prospettive: atti del convegno "La didattica dei beni culturali", Taranto 28-29 novembre 1986. Milano: Vita e Pensiero, 1988. MATTOZZI, I.; BURZOTTA, Di Blasi (a cura di). Dalle fonti alla storia: i Paleoveneti al museo nazionale atestino. Venezia: Comune di Venezia, 1989.

MATTOZZI, I; R DI BLASI BURZOTTA. Cura ed elaborazione del quaderno didattico per la mostra “Giambattista Tiepolo”. Milano: Skira, 1996.

MATTOZZI, I, Museo e insegnamento della storia in Storia e territorio, Università degli Studi di Ferrara, Corso di perfezionamento a distanza in Didattica dell'antico, Ferrara, 1999, p. 57-110. MATTOZZI, I. (a cura di). Istituzioni, beni culturali, didattica In: "Scuola Viva", a. XXVII (1991), nn. 6/7.

MATTOZZI, I. Dalla ricerca storica specialistica alla ricerca storico-didattica In: E. FICARELLI; G. ZACCHÉ (a c. di). La didattica negli archivi. Atti del seminario di studi "L'officine della storia. Le fonti della ricerca" (Carpi, 29 aprile 1999). San Miniato: Archilab, 2000. p. 35-55.

MATTOZZI, I.; PERILLO, E. (a cura di). La filanda di Campocroce. Proposta di ricerca storico-didattica. Mogliano Veneto: Comune di Mogliano, 1980.

MATTOZZI, I. Il Museo nella didattica della storia, guida per gli insegnanti. In: "Alla 
Scoperta Dei Paleoveneti nel territorio Padovano. Itinerari didattici tra i reperti del Museo Civico", Comune di Padova, Padova: Assessorato alla Pubblica Istruzione Servizi Educativi, 1989. MATTOZZI, I. La trasposizione didattica. In: Didattica dell'antico, Università degli Studi di Ferrara, Corso di perfezionamento a distanza in Didattica dell'antico, Ferrara 1999, pp. 11-107. MATTOZZI, I.. GIOVETTI, P (a cura di), La raccolta di Giuseppe Acerbi, (percorso didattico nel Museo Egizio di Palazzo Te). Mantova: Comune di Mantova, 1993.

NARDI, E (a cura di), Imparare al Museo. Percorsi di didattica museale. Napoli: Tecnodid editrice, 1996.

PANZERI, P Didattica museale in Italia Rassegna di bibliografia. Roma: Comune di Roma Assessorato alla Cultura, Fratelli Palombi Editori, 1992.

ROSSINI, O (a cura di). Museologia e didattica museale. Cangemi: Roma, 1999.

ZUCCHINI, G. L. Educare all' ambiente, una lettura didattica dei beni naturali e culturali. Firenze: La Nuova Italia, 1990.

ZUCCHINI, G.L. Didattica del museo e dell'immagine. Brescia: La Scuola, 1989.

\section{NOTAS}

${ }^{1} \mathrm{Na}$ sessão Il museo parla al pubblico attraverso il suo apparato didattico (p. 165-210), do livro escrito por Umberto Eco. Museo e comunicazione in Il museo parla al pubblico 1989-90. Atti del convegno di Bologna, 19-21, ottobre 1989, Roma, UPI, Provincia di Bologna, Editoriale TEST, 1990, podemos encontrar importante contribuição para a discussão das acepções didáticas dos bens materiais .

${ }^{2}$ I. Mattozzi, Dalla ricerca storica specialistica alla ricerca storico-didattica in E. Ficarelli e G. Zacché (a c. di), La didattica negli archivi. Atti del seminario di studi "L'officine della storia. Le fonti della ricerca" (Carpi, 29 aprile 1999), Archilab, San Miniato, 2000, p. 35-55.

I. Mattozzi, R. Di Blasi Burzotta (a cura di), Dalle fonti alla storia: $i$ Paleoveneti al museo nazionale atestino, Venezia, Comune di Venezia, 1989.

I. Mattozzi, Il Museo nella didattica della storia, guida per gli insegnanti, in "Alla Scoperta Dei Paleoveneti nel territorio Padovano. Itinerari didattici tra i reperti del Museo Civico", Comune di Padova, Assessorato alla Pubblica Istruzione Servizi Educativi, Padova 1989.

${ }^{3}$ Ver http://www.ibiblio.org/wm/rh/

http://www.mondimedievali.net/Europa/castberry01.htm

http://www.liu.edu/cwis/cwp/library/sc/ducdeberry/ducdeberry.htm)

Recebido: $15 / 02 / 08$

Aprovado: 07/03/08

Contato:

Universitá di Bologna

p.za S. Giovanni in Monte, 2

40124

Bologna

ITALIA

E-mail: ivo.mattozzi@unibo.it 